\title{
Determinants of Psychological Work Environment Among School Teacher in Malaysia
}

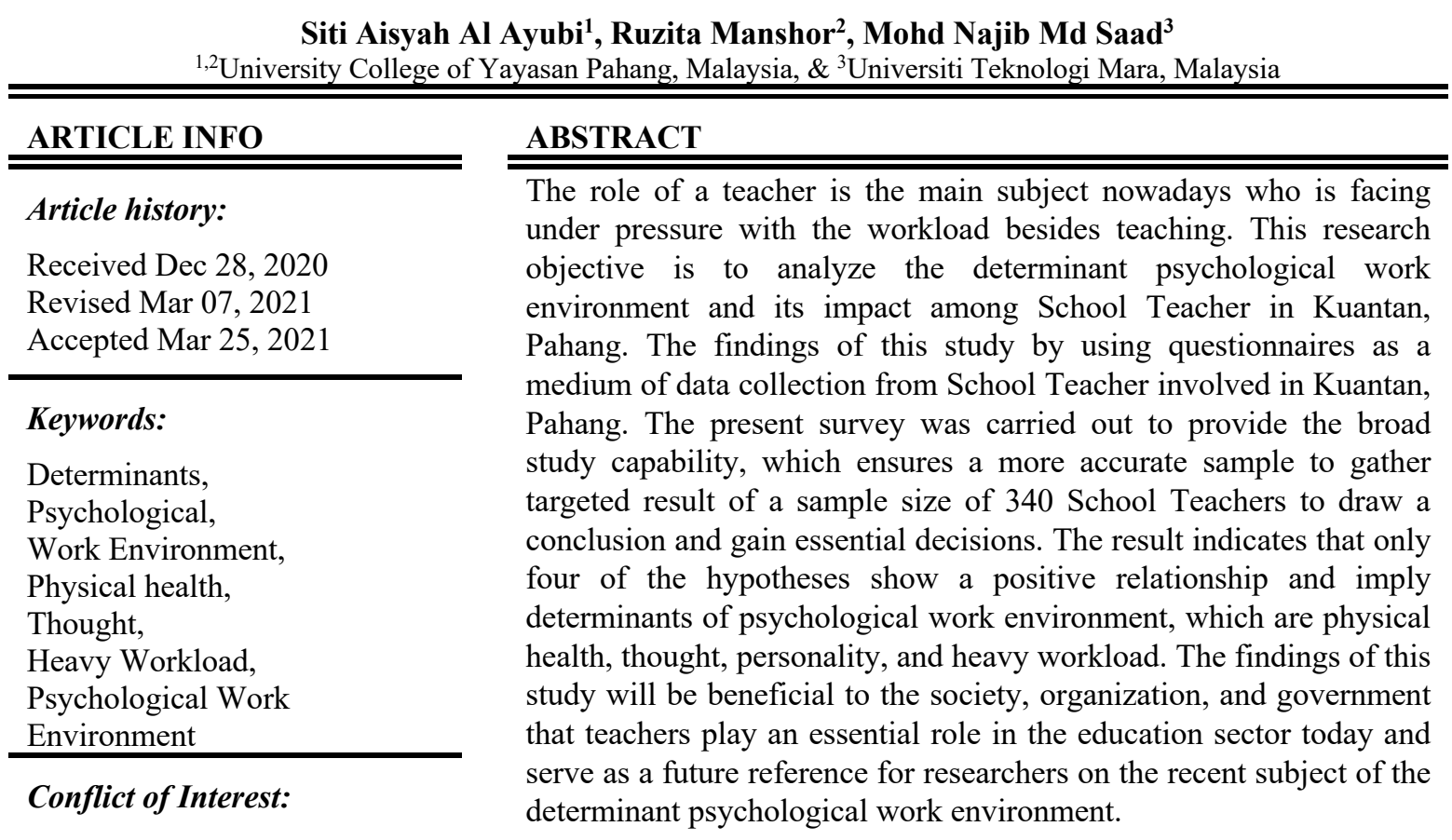

None

Funding:

None

Corresponding Author: Siti Aisyah Al Ayubi, Faculty of Management, University College of Yayasan Pahang, 26060 Kuantan, Pahang. E-mail: sitiaisyahalayubi@gmail.com

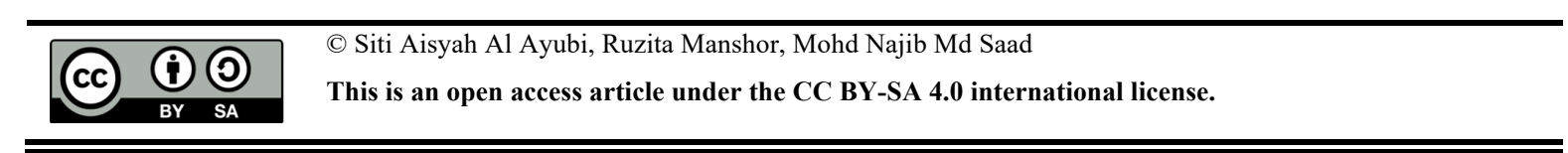

\section{Introduction}

School Teacher is an essential foundation component in achieving the mission and vision of an education sector. In an age of technology, the role and responsibilities of teachers are pretty demanding and challenging (Nurwahida, Faradila, Lim Wei \& Syeda 2017). According to the author, apart from teaching, teachers are also burdened with clerical duties, be facilitator, motivator, planner, advisor, curriculum advisor or club leaders, sports coaches, manage student data, manage student discipline, and many more. Thus, to meet the teaching standard, this study promoting the teacher's needs a working environment that allows them to work freely without any psychological factor such as intrusive thought, which restrains them from achieving their full potential in educating. The study aims to analyze the determinants of psychological work environments among school teachers in Kuantan, Pahang.

An immensity of the dimension of literature signified that a psychological work environment led to commodious worker's welfare and behavior toward productivity (Azahar Che Latif, Najib Ahmad Marsuki, Norlisah Matsha. 2014) \& (Nita, 2017). An implication of the comprehensive journal definite the association on the relationship of the psychological resilience, work environment, the behavioral, emotional distress 
influences how the profession is regarded. The psychological conditions of the people struggled with stressful experiences (Jameel \& Hala S. 2014). Moreover, the research findings that a person is absent and the number of employee turnovers are related to a person's job satisfaction (Azahar Che Latif, Najib Ahmad Marsuki, Norlisah Matsha. 2014) \& (Nita, 2017).

According to Herzberg's Theory, the individual is not content with the satisfaction of lower-order needs at work; for example, those needs associated with pleasant working conditions (Frederick Herzberg, Psychologist, 1964), because satisfied employees will tend to be more productive, creative and committed to their job (Ovidiu, 2013). Specifically, many proven theories of the psychological factors that encouraged an act as health protection and positive work environment suggested how individual happiness should be fostered and the prevalence of the trends (Nita, 2017). The purpose of building a positive work environment distinguished all the causes of emotional distress, personality disorder, anxiety, and frustration, and less worry (Nita, 2017). The essential requirements for adapting a healthy psychological work environment on this study directed toward promoting the better invention of each School Teacher needs concerning their state of physical health, good personality, and positive thought that to satisfy their basic needs which encourage an optimal state of psychological work environment concerning cope heavy workload and vulnerable pace organization.

In the era of the technology revolution, the top priority of a teacher's job can do multitasking at once. Most importantly, teachers need to prepare teaching methodologies in order to present effective learning. However, nowadays, teachers are specifically assigned additional duties that include adding and modifying personal information of the students, fees collection, providing textbooks, updating log books, analyzing which student is eligible to receive financial aid, and other additional clerical duties (Nurwahida, Faradila, Lim Wei \& Syeda 2017). According to the authors, school teachers have not only the responsibility of teaching students, but also they need to handle various clerical works that are sometimes quite difficult to handle.

Education Minister of Malaysia, Dr. Maszlee Malik, in his to-do list when he took over as education minister in May 2018, promised to reforms on teacher workload and being stressed that teachers should focus on nurturing and educating students instead of being burdened with clerical work (Hazlina, New Straits Times, 2018) and teacher-facing heavy workload is not a new issue. Nevertheless, stress can be a neutral, negative, or positive experience (Alexandra, 2017). Besides teaching, the vast mindless workload also affected the teacher's emotional, personality, thought, or physical health; (Jayne, 2019) or both such as anxiety, stress, fatigue, depression, and frustration as remark as a negative experience. The Star online dated 14th February 2014, reported that a male teacher who allegedly hurt four students of Sekolah Menengah Jenis Kebangsaan (SMJK) in Sitiawan could be undergoing stress and mental problems.

Thus, this research will focus on the determinants of psychological work environment among school teachers in Kuantan, Pahang, as it will benefit society, organization, and government and serve as a future reference for researchers on the recent subject of the psychological work environment.

\section{Research Objectives}

The general purpose of this research is to explore the determinants of psychological work environment in the context of School Teachers in Kuantan. The specific objectives of this study are to:

- investigate the relationship between physical health and psychological work environment.

- analyze the relationship between thought and psychological work environment

- examine the relationship between personality and psychological work environment

- identify the relationship between heavy workloads and psychological work environment

\section{Literature Review}

\subsection{Education System in Malaysia}

A School Teacher, in some contexts, is an educator who helps students to acquire knowledge, capability in teaching with high integrity standards. Rather than teaching, the teacher's professional duties did extend beyond formal teaching. The teacher, who is noble in character, progressive, and scientific in outlook, committed to upholding the aspirations of the nation and cherishes the national cultural heritage, ensure the development of the individual and the preservation of a united, democratic, progressive and disciplined society (The Philosophy of Teacher Education, 1982:14) \& (Malaysia, 1982).

The education system in Malaysia is divided into preschool education, primary education, secondary education, post-secondary education, and tertiary education. The Ministry of Education (Kementerian 
Pendidikan) is regulated to all education in Malaysia and each state and federal territory school delegated by the Education Department for taking care of educational matters to bring the organization's efficient activity of the organization's school (Malaysia, 2012). The primary legislation governing education is the Education Act 1996 (Malaysia, 2012).

"Education in Malaysia is an ongoing effort towards further developing the potential of individuals in a holistic and integrated manner, to produce individuals who are intellectually, spiritually, emotionally, and physically balanced and harmonious based on a firm belief in and devotion to God. Such an effort is designed to produce Malaysian citizens who are knowledgeable and competent, who possess high moral standards, and who are responsible and capable of achieving a high level of personal well-being as well as being able to contribute to the betterment of the family, society and the nation at large" (Ministry of Education, 2008).

Malaysian Educational policy is the transformation of the National Philosophy. As documented in the Ministry of Education circular 1988, the policy focuses on improving the quality of output to meet the workforce requirements and producing disciplined citizens who have high moral values and good work ethics. It aims to inculcate and nurture national consciousness by promoting common ideas, values, aspirations, and loyalties; fostering national unity; producing a workforce for economic and national development; and instilling desired moral values in students to make practical contributions towards nationbuilding. (Hazri, Abdul Rashid, Nordin \& Reena, 2014).

The Sixth Malaysian Plan (1990-1995) brought about a significant focus on expanding educational opportunities, increased access to all levels of education, and strengthening and improving quality education. In the Seventh Malaysian Plan (1996-2000), the government improved the workforce needs in the fields of science and technology and boosted the objectives of education and training to produce an ample amount of skilled and qualified workers. The Ninth Malaysian Plan (2006-2010) intends to move the economy up the value chain and intensify human capital development into a knowledge-based economy. Initiatives undertaken have improved the quality of accessibility to education, provided tertiary education of international repute, nurtured R\&D and innovation capability, and continued upgrading the quality of teachers and academic staff. Education is one of the most potent elements for bringing about changes required to achieve sustainable development, and teachers are the main actors in this process. Teacher education training is a bridge for developing the capacities of teachers to deliver sustainable educational approaches.

\subsection{Relationship Between Physical Health with Psychological Work Environment}

The balancing act of managing clerical work with the educational duties of a teacher becomes tougher; and this also affects the mental and physical health of teachers as it causes stress, anxiety, and low job satisfaction as the teachers are required to concentrate on sub-important documenting tasks instead of following their passion of teaching and guiding students (Nurwahida, Faradila, Lim Wei \& Syeda (2017). House (1981), reviewing studies of social support in the workplace, found that social support may decrease stress and other related health problems and improve the well-being of employees.

Physical health is critical for overall well-being and is the most visible of the various dimensions of health, social, emotional, spiritual, and environmental health. (John Koshuta, 2018). Physical health and psychological condition are fundamentally linked. There are multiple associations between psychological and physical health that significantly impact employees' quality of psychological work behavior and generate counterproductive work behavior towards the organization. The World Organization (WHO) defines that: "health as a state of complete physical, mental and social well-being and not merely the absence of disease or infirmity" (Youngeun \& Eujin, 2019), and the author states that mental disease, in particular, has become considerably more prevalent because of overwork, genetic effects, surrounding environment, and etcetera. A stressful event can provoke a psychological and physiological response in various systems within an individual (Jenny, Kristin \& Mauren, 2017). Prolonged exposures to stress result in exhaustion of physical resources, leaving one vulnerable to many mental and physical problems. A healthy workplace is a place where everyone works together to achieve an agreed vision for the health and well-being of workers and the surrounding community (Samantaray, 2014), and the author stress that it is a must to provides all members of the workforce with physical, psychological, social and organizational conditions that protect and promote health and safety.

The International Labour Organization (ILO) notes that: Workplace Well-being relates to all aspects of working life, from the quality and safety of the physical environment, to how workers feel about their work, their working environment, the climate at work, and work organization. Measures for workplace well-being aim to complement OSH (Occupational Safety and Health) measures to ensure workers are safe, healthy, 
satisfied, and engaged at work. Worker's well-being is a critical factor in determining an organization's longterm effectiveness. Many studies show a direct link between productivity levels and the general health and well-being of the workforce (European Agency for Safety and Health at Work, 2013).

\subsection{Relationship Between Thought with Psychological Work Environment}

Thought is underlying many human actions and interactions with opining, representing, reasoning, conceiving-all have their place and conceiving- all have the function and more practical of the conception of thinking (Martin, 1976). Thought disorder refers to disorganized thinking as evidenced by disorganized speech and including derailment, poverty speech, tangentially, illogicality, perseveration, and thought blocking (Yudofsky, Hales \& Robert E, 2002); it is often a symptom of mania, and less often it can be present in other mental disorders such as depression. Besides, intrusive thoughts are unwanted thought or images that someone has distressing or disturbing (Martin \& Sally, 2017); the author state the content of unwanted intrusive thoughts often focus on sexual or violent or socially unacceptable images. Some unwanted intrusive thoughts consist of repetitive doubts about safety, religion, death, or worries about questions that cannot be answered with certainty, and some are just weird thoughts that make no apparent sense. These thoughts are universal and are common in everyday life (Martin \& Sally, 2017).

This interpretation can lead to or maintain an adverse effect and increase levels of anxiety or lower mood. (Moulding, Coles, Alcolado, Alonso, Belloch, Bouvard, Clark, Doron, Fernandez, \& Garcia 2014). Universiti Putra Malaysia (UPM) counseling division senior counselor Siti Fatimah Abdul Ghani said, "Everyone experiences stress from time to time, and this is normal. On the other hand, mental illness is any condition that makes it difficult to function in daily life. It can affect your relationships, your job or prevent you from reaching an otherwise attainable goal. Mental illness can range from anxiety and mood disorders, which have a severe and tangible effect on your emotions and motivation, to psychotic disorders such as schizophrenia, which affect perceptions or senses, with symptoms like delusions or hallucinations. Living with any of these can be debilitating. We rely on our senses, emotions, and perceptions to get us through the day. When any of those fail, it can make life difficult." (Rozana, 2018, New Straits Times). Schizophrenia is a chronic and severe mental disorder that affects how a person thinks, feels, and behaves (National Insitute of Mental Health). Therefore, the psychological environment is the set of characteristics of the work environment that affect how the worker feels, thinks, and behaves (Jameel K \& Hala.S, 2014). Thought is fundamentally linked with psychological factors.

\subsection{Relationship Between Personality with Psychological Work Environment}

Significant social environments are personality traits that elicit particular social behavior and responses from (Snyder 1981). Allport (1937) defined the "personality as the dynamic organization within the individual of those psychophysical systems that determine his unique adjustments to his environment" (Murray \& Ann, 2003).

The individual personality is related to the result of heredity and environment; indicate that the early phase of the psychological work environment tried to identify individual behavior characteristics, including hardworking, talented, lazy, aggressive, loyal, and ambition (Stephen \& Timothy, 2017). The author states the organization's reason to measure personality is that research has shown personality tests help hire decisions and assist the organization management forecast on selecting the employees to fit in the job (Stephen \& Timothy,2017).

Moreover, the personality trait exhibit when the people's characteristics patterns of thought, feeling, and behaviors. The more consistent the characteristics over time, and the more frequently it occurs in diverse situations, the more critical that trait is in describing the individual personality (Stephen \& Timothy, 2017). Many researchers debated that the concept of personality types remains controversial in psychology, with hard scientific proof difficult to find. (Stephen \& Timothy, 2017) According to a psychologist, highlighted of the big five significant traits underlies personality traits, which are introversion/extroversion, openness, conscientiousness, extraversion, agreeableness, and emotional stability. Thus, the researcher has found the relationship between personality dimensions and job performance. According to the authors' review that, "The preponderance of the evidence shows that individuals who are dependable, reliable, careful, thorough, able to plan, organized, hardworking, persistent and achievement-oriented tend to have higher job performance in most if not all occupations."

\subsection{Relationship Between Heavy Workload with Psychological Work Environment}

'Good infrastructure, equipment, and facilities in schools complement good teaching' and' less paperwork, more time to teach' (The Star Mail, Samuel). The article report proposed improvising duties especially on 
lessen the workload, besides teaching and arises towards education system nowadays. Stress in the workplace is a widespread problem and has become a significant public health issue due to its adverse effects on physiological and mental health (Lee, Joo, \& Choi, 2013).

Responsibility load has important implications for employee work stress, turnover intention, and emotional commitment (Kirmeyer \& Dougherty, 1988). The workload is the individuals' perception that the amount of work they have to do is beyond normal (Cedoline, 1982). Besides, Meyer and Allen (1997) stated that workload has a negative effect on employees' emotional commitment. In other words, workers are expected to react negatively to high workload levels when they expect or feel entitled to low workload levels based on their occupational role (Michael \& Jiafie, 2015). When one's workload is incongruent with occupational role norms, it is expected that workers will see this as a violation of the implicit expectations they have for their working conditions, increasing feelings of illegitimacy and, in turn, influencing psychological strain (Michael \& Jiafie, 2015). The heavy workload has a significant relationship with the deviant psychological work environment.

\subsection{The Psychological Work Environment}

According to (Jameel \& Hala. S 2014), the psychological conditions people experience in the workplace, often referred to as the psychological work environment, have become a standard component in studies of stress and occupational health. Furthermore, the vitally important goal of all business organizations is to increase their productivity and decrease the cost of production and make high profits. Even though few of the certain organization are not focusing on increasing their productivity, the result makes hugely wrongly view how important is to understand the relation of performance and productivity by giving their employees (David Finkel, 2018).

Many studies indicate that the one major factor that impacts the psychological and motivation level of employees' relation is the psychological work environment (Nita, 2017, Jameel \& Hala.S, 2014, Malin, Lotta \& Irene, 2018). Many studies have also proved that many employees leave their organization due to bad experiences with their immediate management (Azahar Che Latif, Najib Ahmad Marsuki, Norlisah Matsha. 2014). This shows that the determinant of psychological work environment plays essential findings of the study. Many studies indicate that the one major factor that impacts the psychological and motivation level of employees' relation is the psychological work environment (Nita, 2017, Jameel \& Hala.S, 2014, Malin, Lotta \& Irene, 2018). Many studies have also proved that many employees leave their organization due to bad experiences with their immediate management (Azahar Che Latif, Najib Ahmad Marsuki, Norlisah Matsha. 2014). This shows that the determinant of psychological work environment plays essential findings of the study.

Thus, this study will implicate the psychological work environment that will measure from the four dimensions that impact the psychological work environment among the teacher: physical health, thought, personality, and heavy workload. Psychological factors in the work environment must define widely related to these influences and their effects and have to a great extent, been seen in cynical alternative forms of the action. All these factors together also have an impact on the productivity of an employee. Therefore, to gain better studies result, it becomes essential that correctly indicating the determinants of the psychological work environment.

3.7 Research Framework 


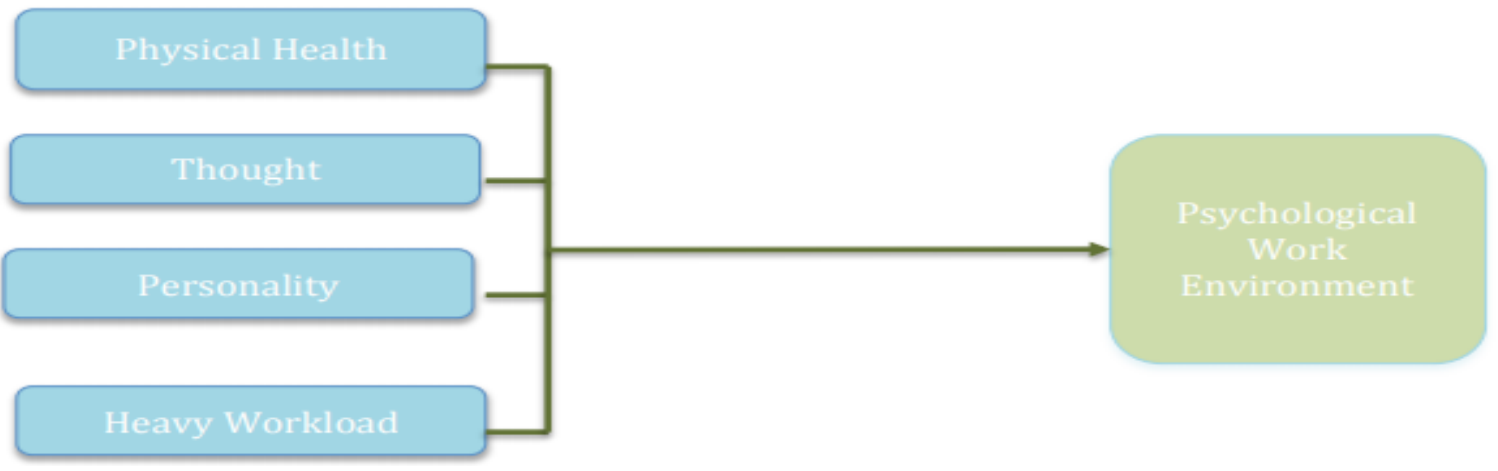

Figure 1. Research Frameworks

\subsection{Conceptual Research Framework}

The findings of the studies are to explore the aspects of the determinant psychological work environment that correlated with the psychological work environment. Many studies had come out many perspective theoretical approaches on developing an understanding of those relationships. Thus, the recent primary variable will be discussed with a contemporary perspective and newfound out of the studies by underlying the factor impact-related on psychological well-being. Figure 2.9 illustrated the proposed conceptual framework to the finding of the research. Each of the factors on psychological work environment has correlated between psychological work environments. According to (Jameel \& Hala.S, 2014), the psychological conditions of people in the workplace, often referred to as the psychological work environment, have become a standard component in studies of stress and occupational health. The features of psychological work environment features of the work environment, which are relevant to worker behavior. Thus, the work behavior is predicted due to the psychological work environment of emotional distress (Jameel \& Hala.S, 2014).

\subsection{Research Hypothesis}

The hypotheses are as follow:

i. HO1: There is a significant positive relationship between physical health and psychological work environment.

ii. HO2: There is a significant positive relationship between thought and psychological work environment.

iii. HO3: There is a significant positive relationship between personality and psychological work environment.

iv. HO4: There is a significant positive relationship between heavy workloads and psychological work environment.

\section{Method}

\subsection{Research Design}

The research theory designates to the set of beliefs concerning the nature of the reality being investigated (Bryman, 2012). To execute the research accurately, the methodology will use the quantitative method for this study. This research discovered the relationship between the factors and the psychological work environment among school teachers in Kuantan Pahang. The quantitative research method deals with quantifying and analyzing variables to get results (Oberiri, 2017), and it involves the utilization and analysis of numerical data using specific statistical techniques to answer survey questions. An independent variable (sometimes called an experimental or predictor variable) is a (sometimes called an outcome variable) (Oberiri, 2017). Thus, using the quantitative method clarifies the variable (physical health, thought, personality, and heavy workload) correlated with the dependent variable (psychological work environment). 
4.2 Questionnaire Design

Table 1. Measurement items

\begin{tabular}{|c|c|c|}
\hline Variables & Source & Scales Design \\
\hline Physical Health & $\begin{array}{l}\text { Jameel and Hala } \\
\text { 2014, (Malin, } \\
\text { Survey 2018) }\end{array}$ & Likert Scales \\
\hline Thought & $\begin{array}{l}\text { Jameel and Hala } \\
\text { 2014, (Raplh, } \\
\text { John, Julie, Sigrid, } \\
\text { Jean, Hillary, David } \\
\text { \& etc 2018),(Malin, } \\
\text { Survey 2018) }\end{array}$ & Likert Scales \\
\hline Personality & $\begin{array}{l}\text { Jameel and Hala } \\
\text { 2014,(Raplh, John, } \\
\text { Julie, Sigrid, Jean, } \\
\text { Hillary, David \& etc } \\
\text { 2018) }\end{array}$ & Likert Scales \\
\hline Heavy Workload & $\begin{array}{l}\text { Jameel and Hala } \\
\text { 2014,(Malin, } \\
\text { Survey 2018) }\end{array}$ & Likert Scales \\
\hline Psychological Work & Jameel and Hala & \\
\hline Environment & 2014 & Likert Scales \\
\hline
\end{tabular}

Table 2. The questionnaire design

\begin{tabular}{clc}
\hline PART & ITEMS & \multicolumn{1}{c}{$\begin{array}{c}\text { No. of } \\
\text { Item }\end{array}$} \\
\hline A & $\begin{array}{l}\text { Demographic } \\
\text { i. Gender } \\
\text { ii. Age } \\
\text { iii. Race } \\
\text { iv. Working Experience } \\
\text { v. Education } \\
\text { vi. Current Position }\end{array}$ & 6 \\
\hline B & Physical Health & \\
\hline C & Thought & 6 \\
\hline D & Personality & 5 \\
\hline E & Heavy Workload & 5 \\
\hline F & Psychological Work Environment & 5 \\
\hline
\end{tabular}

These research study designs have contain 21 items to reach the relationship with 6 items of dependent variables. 


\subsection{Respondents}

Three hundred forty respondents had been answered and collected through the paper-based questionnaire form, distributed in each of the secondary schools. The population of school teachers in secondary school is about 2684 people aged 520 from male and 2126 from females. Thus, the respondent must acquire reached 337-340 respondents according to the (Krejcie \& Morgan Table,1970) - sample size calculation table. The data analyzed using the following method are; Frequency Analysis, Descriptive Analysis, Reliability Analysis, Pearson's Correlation Analysis, and Multiple Regression Analysis.

\section{Results and Discussion}

\subsection{Multiple Regression Analysis}

Regression analysis is a helpful statistical method that can be leveraged across an organization to determine the degree to which particular independent variables influence dependent variables (Ben, 2018). In this study, the method slightly computes using analysis of bivariate correlation.

Table 3. Regression analysis the relationship of determinants psychological work environment

\begin{tabular}{|c|c|c|c|c|c|}
\hline \multirow[b]{3}{*}{ Model } & \multicolumn{3}{|c|}{ Coeffiecient $^{\mathrm{a}}$} & \multirow[b]{3}{*}{$\mathrm{t}$} & \multirow[b]{3}{*}{ Sig. } \\
\hline & \multicolumn{2}{|c|}{ Unstandardized Coefficients } & \multirow{2}{*}{$\begin{array}{c}\begin{array}{c}\text { Standardized } \\
\text { Coefficients }\end{array} \\
\text { Beta }\end{array}$} & & \\
\hline & B & Std. Error & & & \\
\hline 1 (Constant) & 1.075 & .127 & & 7.209 & .000 \\
\hline Physical_Health & .236 & .035 & .234 & 1.851 & .003 \\
\hline Thought & .114 & .031 & .127 & .982 & .024 \\
\hline Personality & .017 & .031 & 019 & .124 & .065 \\
\hline Heavy_Workload & .373 & .030 & .420 & 2.267 & .000 \\
\hline $\mathbf{R}$ & & .7 & & & \\
\hline R Square & & .6 & & & \\
\hline Adjusted R Square & & .6 & & & \\
\hline
\end{tabular}

**: $62.4 \%$ of Dependent Variable (DVs) justifies each the Independent Variable (IVs), and the $37.6 \%$ is the other factors that are not related in this study. Thus, the analysis has stimulated to suggest closely the other factors related to Dependent Variables (DV).

\subsection{Discussion}

The first objective of this study is to determine the relationship between physical health and the psychological work environment. The findings of the resulting study indicate that physical health has a significant relationship with the psychological work environment with the beta value is .234 (23.4\%), and the $\mathrm{p}$-value is less than 0.05 . The results proved that physical health has a positive relationship with the psychological work environment, and $\mathrm{H} 1$ was indicated that the hypotheses are supported and accepted.

According to the study (Nurwahida, Faradila, Lim Wei \& Syeda 2017), the author had stated that as due teachers are required to concentrate on sub-important documenting tasks instead of work with the educational duties of a teacher, it have brought impact the mental and physical health of teachers as it causes stress, anxiety and low job satisfaction. The physical environment offers more or less physical safety, and that concerns about accidents or injury are likely to affect psychological well-being (Briner 2017).

The second objective of this study is to determine the relationship between thought and the psychological work environment. The findings of the resulting study indicate that thought has a significant relationship with a psychological work environment with the beta value is $127 ;(12.7)$ and the p-value is less than 0.05 . The result proved that thought has a positive relationship with the psychological work environment, and $\mathrm{H} 2$ was indicated that the hypotheses are supported and accepted. Based on (Jameel \& Halal's, 2014) study said, the psychological environment is, therefore, the set of characteristics of the work environment that affect how the worker feels, thinks, and behaves. Thought had linked with psychological work environment factor.

The third objective of this study is to analyze the relationship between personality and the psychological work environment. The findings of the resulting study indicate that personality has no significant relationship with a psychological work environment with the beta value is $.019(1.9 \%)$ and a p-value is more than 0.05 . 
However, H3 was indicated that the hypothesis is supported but rejected. Thus, the personality does not have a significant relationship with the psychological work environment because the studies of teacher's personality traits are professional behaviors and dominated mainly by higher educated background.

The role of teacher personality endeavors in their influence approach on students and leading educational notion. Many researchers debated that the concept of personality types remains controversial in psychology, with hard scientific proof difficult to find (Stephen \& Timothy, 2017). Hence, personality is an act of the moods, behaviors, and opinions that distinguish one person from another and are observed in people's relations to the environment and social group. The final objective of this study is to determine the relationship between a heavy workload and psychological work environment.

The findings of the resulting study indicate that heavy workload has a positive relationship with a psychological work environment with the beta values is $.420(42 \%)$, and the p-value is less than 0.05 . The result has shown that the heavy workload has a positive relationship with the psychological work environment, and H4 was indicated that the hypotheses are supported and accepted. The result proved that it is similar to the previous study based (Nurwahida, Dinuka, Lim \& Syeda 2017), teachers have been assigned overloaded clerical tasks, and teachers tend to finish up their work up coming home late. Furthermore, teachers have brought work home.

\subsection{Recommendation}

The physical health, thought and heavy workload are the independent variables those the hypotheses were supported and accepted. Furthermore, the analysis study results proved these variables contributed to the signs related to the determinants' psychological work environment. Thus, the recommendation will be applied based on the result of the findings variables to enhance the better solution for the teachers, education sector, and future reference research.

Herewith the following recommendations are:

- The Ministry of Education has reformed the teacher job description that only consisted of teaching in the classroom and providing assistance to teachers suffering from stress and workload that impacted their physical health. Those who have dealt with psychological factors such as anxiety and stress must understand to set boundaries and to help guide them to establish a daily routine. It is also essential to make a vibrant, self-sustaining teaching environment and rewarding to nurture excellence in form career pathways.

- The Ministry of Education has plans to increase the number of motivation seminars among school teachers, including students that related stress and emotional issues, and understand to handle the psychological factor as the educator. The seminar is the training given for the teacher to make them retain the best talent at their jobs to be the educator with dedication, understanding their essential role in the society and the growth mindset of the nation.

- The Ministry of Education may suggest recruiting administration workers in school to lessen the burden of the workload. The daily clerical works such as updating the logbooks, thus, the government bodies should take the initiative to propose using technology in educational systems or updating documentation. The technology system may enable to ensure the tasks placed accurate data such as student records besides the previous practices by entered data manually via paper. This will bring a considerable impact to save on the environment by going reduce paper consumption. The training is also proposed to the teacher regarding the technology system and who consistently underperform. The training is helping support those teachers to get back on track and gain better performance.

- For the future researcher, the study has to expand the scope of the study not for the education sector but can apply for other industries sector research objectives.

\section{Conclusion}

This finding of the study result proved the importance of the factors that determine adverse in the psychological work environment; to discuss the relationship between physical health, thought, personality, and heavy workload that demonstrate significant related with the psychological work environment. Based on the result of analysis findings, physical health, though, and heavy workload had a significant relationship to the determinants of psychological work environment among school teachers in Kuantan, Pahang. Teachers have the most critical job as role models and inspiration in students' lives. This study is lead to provide the recommendation and implication of study towards the Ministry of Education to shape career progression among school teachers for meeting professional standards and future reference research. 


\section{References}

Alexandra Kavushansky, Re-conceptualizing stress: Shifting views on the consequences of stress and its effects on stress reactivity, PLos One. 2017 March

Azahar Che Latif, Najib Ahmad Marsuki, Norlisah Matsha. 2014. Work environment problems and psychological health problems and its relationship with job satisfaction.

Bryman, A. (2012). Social research methods ( $5^{\text {th }}$ ed.). Oxford: Oxford University Press.

Ben Foley, 2018, What is regression analysis and why I should I use it?Source: https://www.surveygizmo.com/resources/blog/regression-analysis/

Cedoline, A. J. (1982). Job burnout in public education: Symptoms, causes, and survival skills. New York: Teacher's College Press.

David Finkel, 'Scale: Seven Proven Principles to Grow Your Business and Get Your Life Back', 2018

European Agency for Safety and Health at Work, 2013, Well-being at work: creating a positive work environment, ISSN: 1831-9351

Frederick Herzberg. The motivation to work, 1964.

Hazri Jamil, Abdul Rashid Mohamed \& Nordin Abd. Razak, Teacher Professional Development in Malaysia: Issues and Challenges. 28 November 2014.

(Hazlina, New Straits Times, 2018) https://www.nst.com.my/opinion/columnists/2018/10/419916/treatteachers-human-beings-not-workhorses by Hazlina Aziz

Jameel K. Kadium. Hala S. Abdul-Wahid. 2014. Evaluation of psychological Work Environment's Effect on Workers' Productivity in Baghdad City

Jayne Thompson, LLB, LLM, What Cause Employee Conflict in the workplace, by Rose Johnson, Reviewed by Updated March 06, 2019

Jenny J.W. Liu, Kristin Vickers, Mauren Red \& Marlyn Hadad, Re-conceptualizing stress: Shifting view on the consequences of stress and its effects on stress reactivity

John Koshuta, 2018. https://study.com/academy/lesson/what-is-physical-health-definition-componentsexamples.html

Kirmeyer, S. L., \& Dougherty, T. W. (1988). Workload, tension, and coping: Moderating effects of supervisor support. Personnel Psychology, 41(1), 125-139.

Lee, J. S., Joo, E. J., \& Choi, K. S. (2013). Perceived stress and self-esteem mediate the effects of workrelated stress on depression. Stress \& Health, 29(1),75-81.

Malin Lohela-Karlsson , Lotta Nybergh, and Irene Jensen, Perceived health and work environment-related problems and associated subjective production loss in an academic population, BMC Public Health (2018)

Martin N. Seif, PSYD \& Sally Winston, 2017, Overcoming Unwanted Intrusive Thoughts Stephen P. Robbins \& Timothy A. Judge, Organizational Behavior, Seventeeth Edition, ISBN 10: 1.292.14630.3, 2017

Martin Heidegger. 1976. What is Called Thinking? Translated by J. Gleen Gray

Malaysia (1982) Teacher Education Division. The philosophy of education (Report of the National Workshop and Survey). Ministry of Education, Malaysia.

Ministry of Education Malaysia. (2008). Education in Malaysia: A journey to excellence. Malaysia: Educational Planning and Research Division

Malaysia. (2015). Eleventh Malaysia Plan 2016-2020: Anchoring Growth on People Putrajaya: Prime Minister's Department Malaysia.

Malaysia. (2012). Laws of Malaysia, Act 550, Education Act 1996

Michael T. Ford and Jiafie Jin (2015), Incongruence between workload and occupational norms for time pressure predicts depressive symptoms. European Journal of Work and Organizational Psychology, 2015 Vol. 24, No. 1, 88-100, http://dx.doi.org/10.1080/1359432X.2013.858701 
Murray R. Barrick, Ann Marie Ryan. 2003 Personality and Work, Reconsidering the Role of Personality in Organizations

Moulding R, Coles ME, Abramowitz JS, Alcolado GM, Alonso P, BellochA, Bouvard M, Clark DA, Doron G, Fernández-Álvarez H, García-Soriano G. Part 2. They scare because we care: The relationship between obsessive intrusive thoughts and appraisals and control strategies across 15 cities. Journal of obsessive-compulsive and related disorders. $2014 \mathrm{Jul}$ 1;3(3):280-91

Nita Sukdeo. 2017. The effect of the working environment on employee satisfaction and productivity: a case study in a clothing manufacturing factory

Nurwahida Faradila Taharim, Dinuka Pramodya Jayasuriya, Lim Wei Xiang \& Syeda Fatima Mazhar. 2017. Clerical Work School Teachers: A burden or a responsibility

Oberiri Destiny Apuke, Quantitative Research Method a Synopsis approach, Vol.6(10), 2017

Ovidiu-Iliuta Dobre. 2013. Employee motivation and organizational performance

Rozana Sani. 2018, https://www.nst.com.my/education/2018/04/361450/coping-student-mental-health

R.B. Briner, 2017 Relationship between work environments, psychological environments, and psychological well-being.

Samantaray Pravamayee, Strategy to develop an effective Workplace Environment, International Journal of Language \& Linguistics, Vol. 1, No.1: June 2014.

Samuel Yesuiah,2014 https://www.thestar.com.my/opinion/letters/2014/12/02/teachers-doing-more-clericalwork/

Snyder, M. (1981). On the influence of individuals on situations. In N. Canto \& J.F. Kihlstrom (Eds.), Personality, cognition, and social interaction. Hillsdale, NJ: Erlbaum

Stephen P. Robbins \& Timothy A. Judge (2017) Organizational Behavior, $17^{\text {th }}$ Edition

The physical environment offers more or less physical safety, and that concerns about accidents or injury are likely to have some effect on psychological well-being.

Yudofsky, Stuart C.; Hales, Robert E. (2002). The American Psychiatric Publishing Textbook of Clinical Psychiatry. Washington, DC: American Psychiatric Association. ISBN 1-58562-0327. OCLC 49576699

Youngeun Kang \& Eujin Julia Kim, Differences of Restorative Effects While Viewing Urban Landscapes and Green Landscapes, Sustainability 2019, 11(7), 2129. 